\title{
TIM Lecture Series Adventures in Innovation: Inside the Rise and Fall of Nortel
}

\author{
John F. Tyson
}

\author{
"The quest is all about relevance and fulfillment." \\ Loving what you do, loving where you do it... within a \\ collaborative community of kindred spirits.
}

\author{
John F. Tyson \\ Industrial designer and senior executive
}

\section{Overview}

The TIM Lecture Series is hosted by the Technology Innovation Management program (carleton.ca/tim) at Carleton University in Ottawa, Canada. The lectures provide a forum to promote the transfer of knowledge between university research to technology company executives and entrepreneurs as well as research and development personnel. Readers are encouraged to share related insights or provide feedback on the presentation or the TIM Lecture Series, including recommendations of future speakers.

The second TIM lecture of 2014 was held at Carleton University on March 18th and was presented by John F. Tyson an industrial designer, inventor, angel investor, and senior executive who spent over 35 years with BellNorthern Research (BNR; tinyurl.com/6vrpyt3) and Nortel Networks (tinyurl.com/lql2bbw). The lecture was inspired by Tyson's recently published memoir: Adventures in Innovation: Inside the Rise and Fall of Nortel (adventures ininnovation.ca) and coincided with the publication of a report on a three-year study into the demise of Nortel Networks (Calof et al., 2014; tinyurl.com/lkk5c3b).

BNR was a telecommunications $R \& D$ organization jointly owned by Bell Canada and Nortel Networks until the 1990s, when it was absorbed into Nortel Networks. Nortel operated for more than 100 years and, at its peak, it was the world's largest supplier of telecommunications equipment. In 2000, Nortel earned revenues of $\$ 30$ billion and employed nearly 100,000 people worldwide (more than 25,000 in Canada, half of whom were in $R \& D)$, but went into decline over the following decade before filing for bankruptcy and ceasing operations in 2009 (Wahl, 2009; tinyurl.com/o786wmp).

\section{Summary}

As with all TIM lectures, the audience was a diverse mix from academia (both professors and students), industry (especially managers, entrepreneurs, and developers), and the public sector. However, given the topic of the lecture, many of those in attendance were alumni of BNR and Nortel, which provided strong resonance for Tyson's reflective, emotive approach. For those unfamiliar with BNR and Nortel, the lecture - and the subsequent discussions and sharing of experiences it prompted provided a clear demonstration of the importance of a strong company culture that provides opportunities for its employees to grow, collaborate, and succeed.

Although much attention is paid today to the demise of Nortel, Tyson encouraged the audience to celebrate its achievements and learn from both its failures and successes. With emphasis on his real-time experiences during the rise and fall of BNR and Nortel, Tyson reflected upon the key lessons he learned that still hold relevance for technology companies today:

1. Falling one step behind is the "kiss of death".

2. Vision matters. An organization's vision is not about public relations slogans, but rather it refers to the clarity of the organization's direction and purpose.

3. Pathfinders matter. Competitors will analyze and try to replicate the actions of a true pathfinder, but by definition, they will always be one step behind.

4. Toys are tools, and the workplace is a playground for innovation. Provide talented individuals with the toys they need to innovate. 


\section{Adventures in Innovation: Inside the Rise and Fall of Nortel}

John F. Tyson

5. Organizations under stress can lose their reason for being.

6. $R \& D$ is complex: it is expensive, multidisciplinary, and collaborative... and it is essential. The " $\mathrm{R}$ " and the " $\mathrm{D}$ " need to be separate, but pulling in the same direction, and neither can be overlooked. Innovation comes from the "R".

7. Innovation means being willing to obsolete or cannibalize your own product.

8. Market leadership cannot be claimed; it can only be assigned by customers, competitors, and industry analysts. Reveling in one's own rhetoric is a deadly $\sin$.

9. Success is a trailing indicator, not a leading indicator. Success is the culmination of past achievements, not a sign you are currently winning the race.

10. Fun matters. If you are not having any fun, stop and ask why. Laughter releases creativity, imagination, and innovation.

11. Corporate culture is the spirit of the organization. It is easy to see and hard to measure, but it is vitally important.

12. Innovation creates new wealth. And, therefore R\&D is an investment, not a cost.

In the discussions that followed each portion of the presentation, audience members shared the lessons they learned from the presentation and injected their own knowledge and experience into the conversation. The audience identified the following additional takeaways from the presentation:

1. The largest risk to an organization is insufficient innovation to stay competitive.

2. An organization's most valuable asset is its people, and to succeed, it must encourage a culture of trust that recognizes how valuable this asset is.
3. A lot of innovation does not succeed in the sense of making money for the company. Therefore, companies should bet on many horses, not just one. However, when one horse wins, managers should avoid thinking they are good at picking winners from that point forward.

4. It is tempting to "chase the money", especially applying for external sources of funding, but these activities can become all-consuming. This is time that is better spent getting to know customers and improving the content.

5. The previous generation is the barrier to success for the current generation. If we want to help young entrepreneurs, we need to get out of their way. Let them try, let them fail, and let them succeed.

This report was written by Chris McPhee.

\section{About the Speaker}

John F. Tyson is an industrial designer, inventor, angel investor and accomplished senior executive who spent over 35 years with Bell-Northern Research (BNR) and Nortel Networks. During this time he focused on product design, R\&D, marketing, and advanced technology. His principles on user-centered design, innovation, and design-based thinking have been detailed in numerous publications and his work has been featured in museums and galleries including the Museum of Modern Art in New York, the National Art Gallery of Canada, the Canadian $\mathrm{Mu}-$ seum of Science and Technology, the Canadian $\mathrm{Mu}-$ seum of Civilization, and the Toronto Design Exchange (DX). His work has also been featured on two Canadian postage stamps.

Citation: Tyson, J.F. 2014. TIM Lecture Series Adventures in Innovation: Inside the Rise adn Fall of Nortel. Technology Innovation Management Review. March 2014: 39-40.

Keywords: innovation, industrial design, user-centred design, company culture, Nortel, Northern Telecom, BNR, Bell-Northern Research 